ARTICLE

https://doi.org/10.1038/s41467-019-09751-4

\title{
Bridging the gap between transition metal- and bio-catalysis via aqueous micellar catalysis
}

Margery Cortes-Clerget (1) ${ }^{1}$, Nnamdi Akporji ${ }^{1}$, Jianguang Zhou², Feng Gao², Pengfei Guo ${ }^{2}$, Michael Parmentier ${ }^{3}$, Fabrice Gallou (1) ${ }^{3}$, Jean-Yves Berthon ${ }^{4}$ \& Bruce H. Lipshutz ${ }^{1}$

Previous studies have shown that aqueous solutions of designer surfactants enable a wide variety of valuable transformations in synthetic organic chemistry. Since reactions take place within the inner hydrophobic cores of these tailor-made nanoreactors, and products made therein are in dynamic exchange between micelles through the water, opportunities exist to use enzymes to effect secondary processes. Herein we report that ketone-containing products, formed via initial transition metal-catalyzed reactions based on $\mathrm{Pd}, \mathrm{Cu}, \mathrm{Rh}$, Fe and $\mathrm{Au}$, can be followed in the same pot by enzymatic reductions mediated by alcohol dehydrogenases. Most noteworthy is the finding that nanomicelles present in the water appear to function not only as a medium for both chemo- and bio-catalysis, but as a reservoir for substrates, products, and catalysts, decreasing noncompetitive enzyme inhibition.

\footnotetext{
${ }^{1}$ Department of Chemistry and Biochemistry, University of California, Santa Barbara, CA 93106, USA. ${ }^{2}$ Chemical and Analytical Development, Suzhou Novartis Pharma Technology Company Limited, 215537 Changshu, Jiangsu, China. ${ }^{3}$ Chemical \& Analytical Development, Novartis Pharma AG, 4056 Basel, Switzerland. ${ }^{4}$ GREENTECH, Biopôle Clermont Limagne, 63360 St Beauzire, France. Correspondence and requests for materials should be addressed to B.H.L. (email: bhlipshutz@ucsb.edu)
} 
W ithin the toolbox of organic synthesis, bio-catalysis has proven to be an extremely efficient approach to inducing high levels of stereo-, chemo, and regio-selectivities ${ }^{1-4}$. While the very recent Nobel prize for "directed evolution" highlights the scope of accessible organic biotransformations $\mathrm{s}^{5,6}$, engineering the reaction medium itself can also lead to significant improvements in terms of enzyme-substrate compatibility, ultimately affording higher yielding processes. Moreover, reaching a certain level of productivity and titer is key for practical and industrial applications, which can be fine-tuned with the proper medium. Bäckvall and coworkers described a hybrid system combining the immobilization of a lipase for the acylation of chiral amines and Pd nanoparticles for racemization of the untouched enantiomers, leading to an efficient metalloenzyme for dynamic kinetic resolution? ${ }^{7}$. Starting from a nonchiral substrate, multicatalyst processes that combine both a chemo- and bio-catalysis sequence oftentimes require a two-phase system, and while well established ${ }^{8}$, the enzymatic component relies predominantly on the presence of water. Any approach where water only is the reaction medium can be quite limiting, as most reaction partners and catalysts are not soluble in aqueous media. Thus, reactions under such conditions either rely on educts that have some element of water solubility, or are assumed to take place on water. Processes involving equilibria, such as an esterification, are also typically prohibited. Nonaqueous bio-catalysis employing organic solvents has emerged to address these issues, especially focused on lipases ${ }^{9}$. Nevertheless, this change in medium is often associated with reduced reaction rates and inactivation or denaturation of the biocatalyst, in addition to the environmental impact associated with use of dipolar aprotic solvents or other VOCs. Greener alternatives for asymmetric biosynthesis ${ }^{10}$ are flourishing, including reliance on supercritical $\mathrm{CO}_{2}{ }^{11}$, ionic liquids ${ }^{12-14}$ and deep eutectic solvents ${ }^{15,16}$ as bio-reaction media. Solvent-free processes ${ }^{17}$ are also employed, with their associated advantages and limitations. While the use of surfactants to prevent protein adhesion to glassware or to mimic in vivo conditions in biochemistry is far from new, most of the systems described rely on emulsions ${ }^{18}$ or reverse microemulsions ${ }^{19}$ using an organic or greasy solvent (e.g., hexane, octane) composing the hydrophobic phase of the system. Those methods are adapted most notably when enzymes and substrates have different solubilities, allowing for a larger contact surface, but by definition, do not avoid the use of organic solvents.

To begin to address the challenges of routinely performing organic synthesis in water under mild conditions, TPGS-750-M was introduced as a "benign by design" surfactant that assembles into atypically aggregated micelles within micelles ${ }^{20}$, averaging ca. $50 \mathrm{~nm}$ in size. This unusual array effectively enables numerous organic reactions with the overarching goal of "getting organic solvents out of organic chemistry" (Fig. 1) ${ }^{21}$. The hydrophobic core is composed of vitamin $\mathrm{E}$ that houses lipophilic substrates and transition metal catalysts.

Switching ${ }^{22}$ from an organic to an aqueous micellar medium has begun to shed light on new rules in effect for transition metalcatalyzed synthetic chemistry, and cross-coupling reactions in particular ${ }^{23}$, in water that are not applicable to conventional organic solvent-based reactions, such as the hydrophobic effect that accelerates reactions under mild conditions ${ }^{24}$. In initially testing the compatibility between nanoreactors composed of TPGS-750-M and alcohol dehydrogenase (ADH ${ }^{25-32}$ in water, it was discovered that not only are these enzymes tolerant of the surfactant but its presence enhances enzymatic activity. One related application of TPGS-750-M to synthetic biotechnology by Balskus describes the acceleration of styrene production by Escherichia coli through interaction with the membrane of the whole cell, as well as a one-pot styrene fermentation then cyclopropanation, confirming that this surfactant is biocompatible 33,34 . We have begun to focus on performing chemo-enzymatic tandem processes to access more complex nonracemic products. While realization of multistep, one-pot processes is particularly attractive under green chemistry conditions, precedent for use of transition metal catalysis preceded or followed by enzymatic catalysis is still marginal, at best, mainly due to the incompatibility of reaction conditions (i.e., $\mathrm{pH}$, temperature, solvent, relative concentrations, etc.) ${ }^{35}$. A few examples combining the use of alcohol dehydrogenase and SuzukiMiyaura $^{36-40}$ or Heck ${ }^{41,42}$ cross-coupling reactions have been reported in water or ionic liquids, but most require the exchange of reaction medium, high temperatures, or specifically designed catalysts. Here we describe an extensive study on the use of nonionic surfactants, and TPGS-750-M in particular, that enable one-pot cascade processes involving both chemo- and bioconversions in the same aqueous medium.

\section{Results and discussion}

Aqueous micellar solutions as the reaction medium. To establish the compatibility of alcohol dehydrogenases and micelles derived from TPGS-750-M in water, asymmetric reductions of four different ketones have been evaluated. These educts included 4-iodoacetophenone (Fig. 2a), 4'-(trifluoromethyl)acetophenone (Fig. 2b), the product from a Heck coupling, 2-ethylhexyl (E)-3(4-acetylphenyl)acrylate (Fig. 2c), and 4-phenyl-but-3-en-2-one (Fig. 2d); all reactions were performed in a phosphate buffer $(0.2 \mathrm{M})$ at $\mathrm{pH}=7$ with and without $2 \mathrm{wt} \%$ of TPGS-750-M. Remarkably, enzymatic superactivity ${ }^{43}$ is observed as the lipophilicity of the substrate increased. Indeed, the presence of the surfactant positively impacted the outcome of the reaction, leading to faster reaction rates. In the case of Fig. 2a, the reduction went to completion far more rapidly in the presence of micelles. Enantiomeric excesses were excellent ( $>99.8 \%$ ee) in both cases. By slightly increasing the lipophilicity of the substrate (Fig. 2b), the reaction plateaued at $80 \%$ conversion in buffer alone, while reaching completion in the corresponding aqueous surfactant solution. The same observation was made in Fig. 2c, with an even greater gap between both media (plateauing at 30 vs. 92\%). The slope discontinuity after $1 \mathrm{~h}$ in buffer may indicate enzyme saturation. The phenomenon was reduced, or suppressed, at a given substrate concentration $(20 \mathrm{mg}$ of enzyme for $0.4 \mathrm{mmol}$ of ketone $[0.056 \mathrm{M}])$, in the presence of TPGS-750-M.

Our rationale for these observations is that under typical conditions, entrance to the enzymatic pocket is eventually hindered by the buildup of water-insoluble substrates and

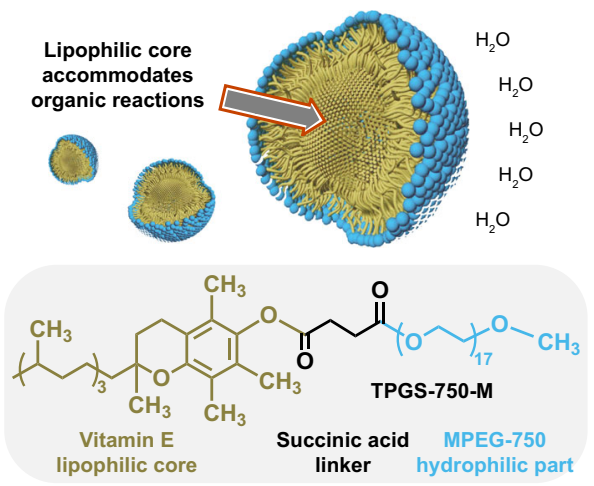

Fig. 1 Nanoreactors for organic reactions. The designer surfactant TPGS750-M forms micelles in water. The hydrophobic core, made of vitamin $\mathrm{E}$, can accommodate organic reactions to take place in water, without the need of additional organic solvent 

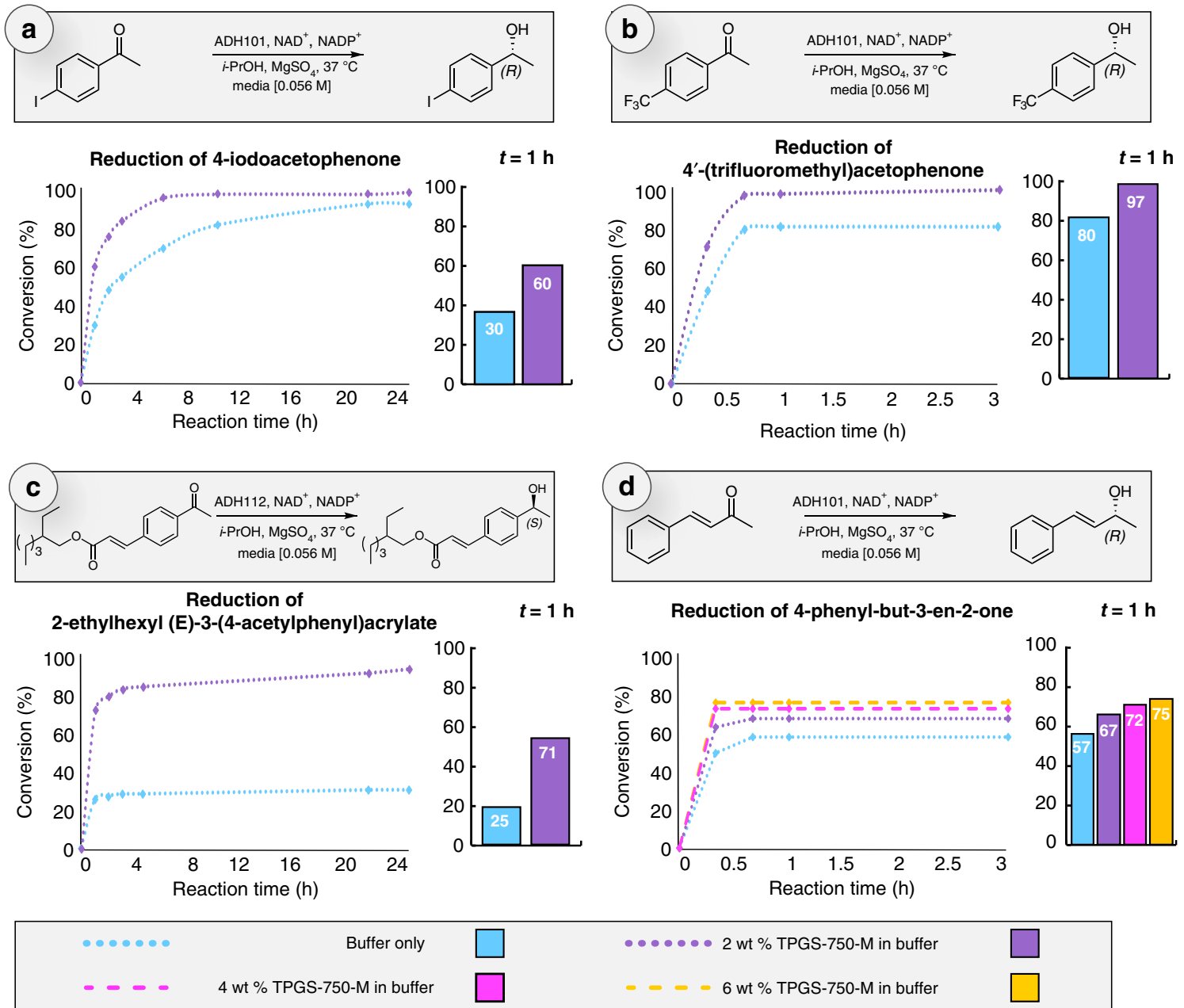

Fig. 2 Ketone reductions with/without TPGS-750-M. For the four examples shown, conversions were monitored until plateauing (curves). A comparison at $t=1 \mathrm{~h}$ is also shown (bars). Reactions in buffer only are displayed in blue. Reactions in 2 wt \% TPGS-750-M/buffer are displayed in purple. Reactions in 4 wt \% TPGS-750-M/buffer are displayed in pink. Reactions in $6 \mathrm{wt} \%$ TPGS-750-M/buffer are displayed in yellow. Plot a describes the reduction of 4iodoacetophenone, plot $\mathbf{b}$ shows the reduction of 4'-(trifluoromethyl)acetophenone, plot $\mathbf{c}$ illustrates the reduction of 2-ethylhexyl (E)-3-(4-acetylphenyl) acrylate, while plot $\mathbf{d}$ shows the reduction of 4 -phenyl-3-en-2-one. Conversions were monitored by HPLC (case $\mathbf{a}$ ) or ${ }^{1} \mathrm{H}$ NMR (cases $\mathbf{b}, \mathbf{c}$ and $\mathbf{d}$ ). Source data are provided as Source Data File

potentially as well due to the more lipophilic products, all looking to gain (re)entry. This leads to incomplete conversions in solely buffered aqueous media, as these data show. In the presence of micelle-forming TPGS-750-M, however, the micelles function both as a desirable solvent (vs. the surrounding water) and as a reservoir, housing and releasing substrates and products as a normal matter of dynamic exchange between micelles ${ }^{44}$. Educts undergoing such a phenomenon find their way to the far less encumbered enzymatic cavity, enabling eventual reduction. Thus, micelles in the buffer help to control both substrate and product concentrations in an aqueous medium, providing a measured supply that does not overwhelm the enzyme, thereby allowing for higher rates of conversion.

To further investigate this hypothesis, the impact of the concentration of TPGS-750-M on reaction rates associated with reduction of both an aryl ketone (Fig. 2c) and an enone (Fig. 2d) were assessed. The former, a keto ester, shows a dramatic difference between the extent of conversion in buffer vs. that in $2 \mathrm{wt} \%$ TPGS-750-M, raising the overall conversion from ca. 30 to over $90 \%$. For the enone, also a challenging substrate for this particular enzyme, its reduction stops at $49 \%$ conversion under purely buffered conditions. While in-depth structural investigations would be needed to understand why such a dramatic stop to this reaction occurred, it is worth mentioning that, by increasing the amount of TPGS-750-M to $6 \mathrm{wt} \%$, the conversion jumps to $75 \%$. These results confirm that increasing the available volume of solvent in this aqueous medium helps to moderate enzyme saturation, supporting a reservoir effect.

Based on these early observations, several other commercially available nonionic surfactants were evaluated under identical conditions (Fig. 3). Reduction by ADH112 of 2-ethylhexyl (E)-3(4-acetylphenyl)acrylate was monitored over time (cf. Fig. 2c). Comparisons between Tween 60 (orange line), TPGS-1000 (light gray line), solutol HS15 (yellow line), SPGS-550-M (aka "Nok"; pink line), PTS-600 (green line), Triton X-100 (dark blue line), labrasol (brown line), and Brij 30 (red line) were compared to the initial results obtained in buffer vs. those from 2 wt \% TPGS-750-M/buffer. In line with expectations, given that each surfactant is capable of serving in a similar capacity, all led to superior results compared to that in buffer alone, again lending further credence to the proposed "reservoir" effect. None, however, outperformed use of $2 \mathrm{wt} \%$ TPGS-750-M. 


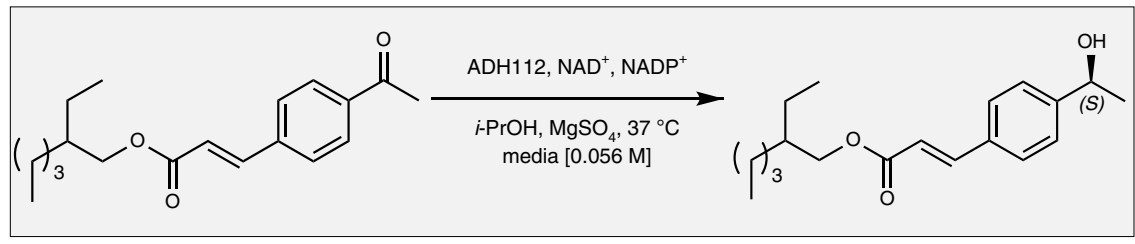

Reduction of 2-ethylhexyl (E)-3-(4-acetylphenyl)acrylate
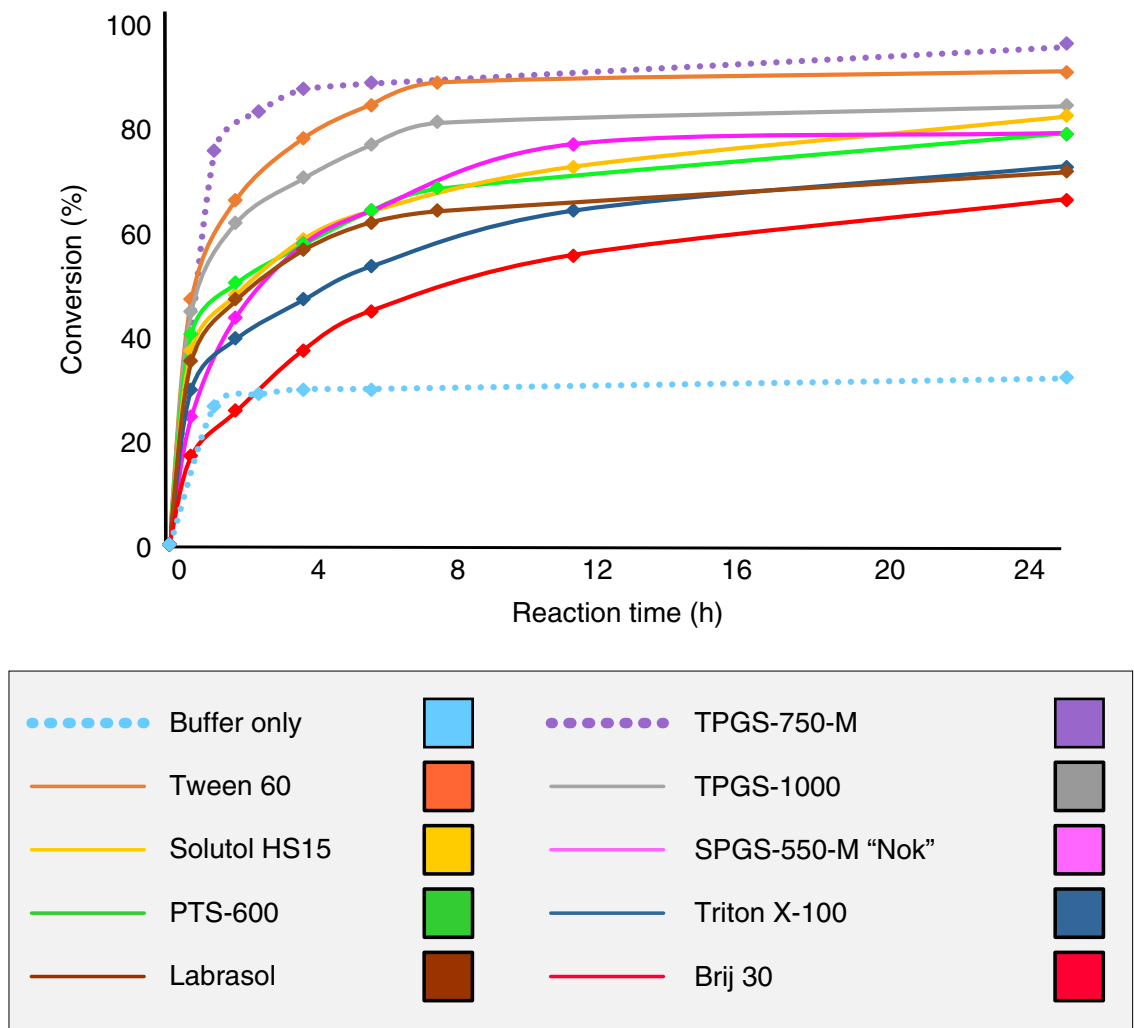

Fig. 3 Comparisons of commercially available surfactants. The reduction of 2-ethylhexyl (E)-3-(4-acetylphenyl)acrylate by ADH112 was performed with a solution of $2 \mathrm{wt} \%$ various commercially available surfactants in a phosphate buffer $[0.2 \mathrm{M}]$ at $\mathrm{pH}=7$ and $37^{\circ} \mathrm{C}$. Conversions were monitored by ${ }^{1} \mathrm{H}$ NMR. Source data are provided as Source Data File

Stability studies. The stability of the enzyme ADH 101 in the presence of TPGS-750-M over time was further evaluated, as surfactants, on occasion, have been reported to denature enzymes ${ }^{43}$. Reduction of 1-(4-(3-hydroxyprop-1-yn-1-yl)phenyl) ethan-1-one at $0.032 \mathrm{M}$ was carried out, and after $24 \mathrm{~h}$ of incubation (Fig. 4a), there was no apparent impact on enzymatic activity. Even at higher substrate concentrations (Fig. 4b, c$[0.064 \mathrm{M}]$ and $[0.128 \mathrm{M}]$, respectively), where only incomplete conversion is achieved (plateaued at $90 \%$ ), no loss of activity was observed after $24 \mathrm{~h}$ of incubation.

Circular dichroism (CD) analyses further confirmed that the enzyme structure is not compromised in the presence of surfactant (see Supplementary Information-Supplementary Fig. 3). ${ }^{1} \mathrm{H}$ NMR spectra, taken with and without surfactant present, overlap perfectly, especially in the amide and $\mathrm{CH}_{3}$ regions where no strong interaction is detected. The absence of signal modification in the $\mathrm{CH}_{3}$ region tends to exclude the hypothesis that the enzyme is inside the micelle (see Supplementary Information-Supplementary Figs. 4-6). The micelles also remain undisturbed by the presence of the protein as the same average diameter was detected by dynamic light scattering analyses of a solution of TPGS-750-M/buffer in the presence of, or in the absence of, ADH101 (see Supplementary Information-Fig. 7).

Sequential tandem catalysis. Following optimization of experimental conditions, sequential two-step, one-pot processes were investigated. Cross-coupling reactions, as well as hydration of alkynes, were directly followed by reduction of each ketonecontaining product by $\mathrm{ADH}$ in the same pot. While some early experimental challenges had to be overcome (vide infra), second-stage enzymatic reductions were found to be compatible with the presence of metals, such as palladium, copper, rhodium, iron and gold, along with various salts that may have been generated from a prior reaction. While most metal-mediated reactions performed in TPGS-750-M/ $\mathrm{H}_{2} \mathrm{O}$ involve substrate concentrations of $0.5 \mathrm{M}$, such conditions are not compatible with the reductases being used, leading to incomplete conversions. Therefore, dilution of the medium was required prior to addition of the alcohol dehydrogenase, from $[0.500 \mathrm{M}]$ to $[0.056 \mathrm{M}]$ (dilution by $\approx 10$ of the ketone), while the temperature was adjusted to $37^{\circ} \mathrm{C}$. Despite a claimed optimal $\mathrm{pH}$ of 7, we observed that the enzyme can tolerate a broader $\mathrm{pH}$ 


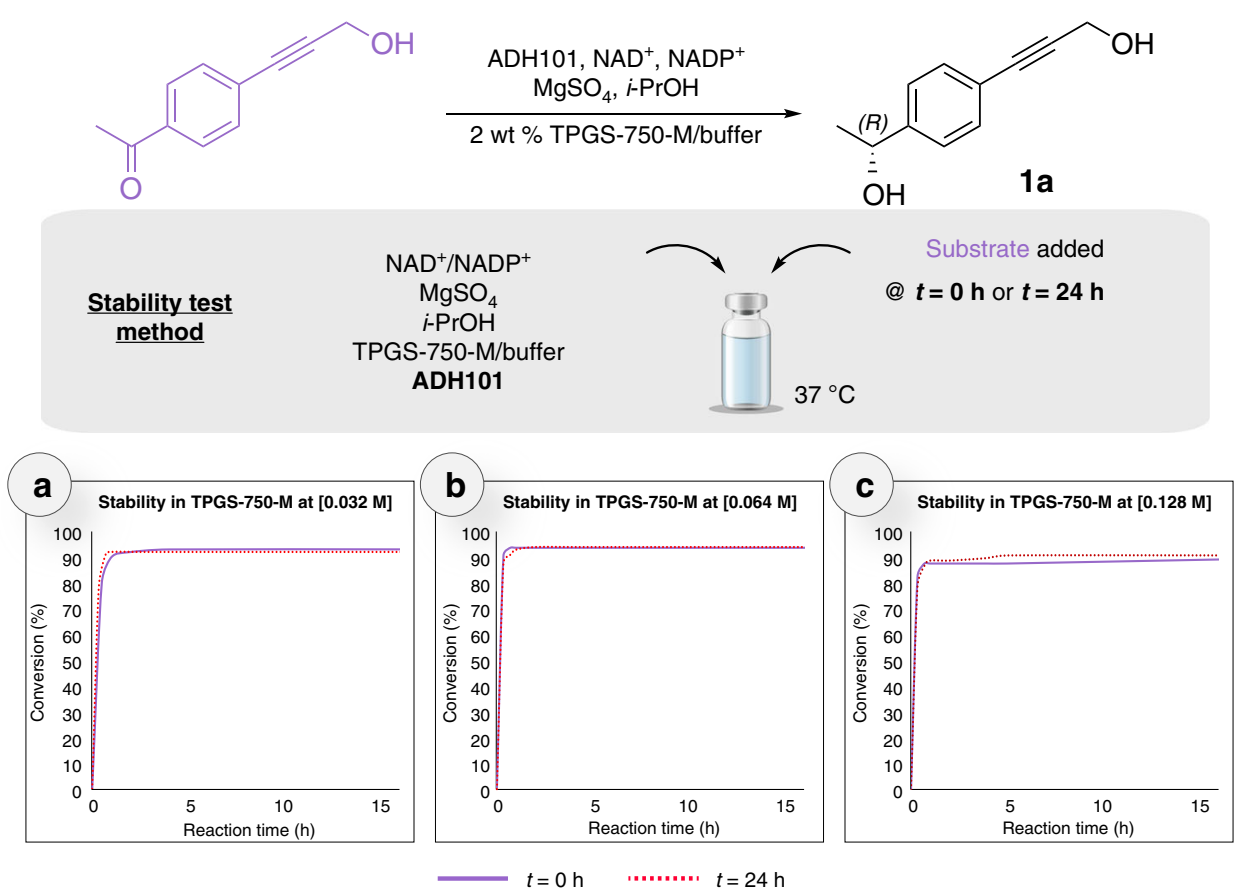

Fig. 4 Stability of ADH101 in aq. TPGS-750-M. The three graphs correspond to the monitoring of the reduction of 1-(4-(3-hydroxyprop-1-yn-1-yl)phenyl)ethan1-one to $\mathbf{1 a}$ at different concentrations relative to substrate $(\mathbf{a}[0.032 \mathrm{M}], \mathbf{b}[0.064 \mathrm{M}], \mathbf{c}[0.124 \mathrm{M}])$. For each graph, two experiments were run: one with no enzyme incubation (purple line), and one with a $24 \mathrm{~h}$ incubation period in the aqueous medium (red dashed line). Conditions: 1-(4-(3-hydroxyprop-1-yn-1-yl) phenyl)ethan-1-one (case a: $20 \mathrm{mg}$, case $\mathbf{b}: 40 \mathrm{mg}$, case $\mathbf{c}: 80 \mathrm{mg}$ ) was added (at $t=0$ or $t=24 \mathrm{~h}$ ) to a solution of ADH101 (20 mg) MgSO 4 (0.8 mg), NAD+ (2.6 mg), NADP+ $(2.4 \mathrm{mg})$ and $\mathrm{i}-\mathrm{PrOH}(0.4 \mathrm{~mL})$ in $2 \mathrm{wt} \%$ TPGS-750-M/buffer $(3.2 \mathrm{~mL})$ at $37^{\circ} \mathrm{C}$ for $24 \mathrm{~h}$. Source data are provided as Source Data File

range (from 4 to 7 ). Cross-coupling reactions in water that involve basic conditions, however, are performed at elevated $\mathrm{pH}$ and hence, an adjustment to neutral-to-acidic conditions is required prior to the biocatalytic step. Tests where addition of an enzyme at a higher $\mathrm{pH}$ followed by $\mathrm{pH}$ lowering to 7 led to no reduction.

The one-pot Pd-catalyzed Sonogashira cross-coupling of an acetoaryl iodide or bromide followed by a biocatalytic ketone reduction was initially studied. Variations in experimental conditions mainly focused on the tolerance of the enzyme to the presence of copper and palladium, although only ppm levels of $\mathrm{Pd}$ are required for these reactions (Fig. 5). Upon generation of an arylated product alkyne, the $\mathrm{pH}$ was decreased to seven, followed by addition of $\mathrm{ADH}$ and the cofactor. Asymmetric reduction of the ketone present in each afforded the corresponding nonracemic alcohols with excellent enantioselectivities ( $>99.5 \%$ ee). The overall yields of the two-step processes are identical to the yield characteristic of the first step alone, attesting to the impressive efficiency of the enzymatic process independent of its modified environment. The background sequence run in the absence of TPGS-750-M leading to product 1a led to a significantly decreased overall yield (less than $50 \%$ ), attesting of the importance of the surfactant in the tandem process.

The enzyme also performed quite well in combination with Heck reactions (Fig. 6) ${ }^{45}$. Both ADH101 and ADH112, being $(R)$ and $(S)$-selective, respectively, towards an acetophenone led to enantiomeric products $(\mathbf{2} \mathbf{b}-\mathbf{e}$ vs. $\mathbf{2 a})$ with essentially perfect fidelity ( $>99.9 \%$ ee). Notably, even $2 \mathrm{~mol} \%$ of Pd (i.e., 20,000 ppm) is well tolerated by the enzyme. Switching to ppm-level gold catalysis, generation of ketones in situ via hydration of alkynes ${ }^{46}$ followed by their reduction to the corresponding nonracemic alcohols led to excellent results as well (Fig. 7a). Lastly, exposure of the same enzymatic system to rhodium, used catalytically to effect an initial 1,4-addition ${ }^{47}$ of a boronic acid to an enone, was of no consequence as ketone reduction took place uneventfully (Fig. 7b). Interestingly, a match/mismatch effect was observed with compound 4 d. Indeed, when the first step is conducted with rac-BINAP, ADH110 transformed only the $4(R)$-enantiomer, leaving the $4(S)$-product intact. ADH105, $(S)$-selective toward acetophenone, performed the reaction only on the $4(S)$-enantiomer. While the reaction conducted with $(R)$-BINAP led to $97.5 \%$ ee $(R)$ for the first step, the final product (in a one-pot process) was obtained with $>99.9 \%$ ee and $>99.4 \%$ de, with $2.5 \%$ of the opposite enantiomer remaining.

To further illustrate the potential for these tandem events in synthesis, the one-pot process could be smoothly extended to three-steps, the product (overall $75 \%, 99.9 \%$ ee) resulting from a sequential 1,4-addition, followed by a nitro group reduction and ultimately, reduction by ADH101 (Fig. 8). The enzyme fully reduced the ketone in less than $2 \mathrm{~h}$, notwithstanding the presence of $\mathrm{Rh}, \mathrm{Fe}$, and other metal salts. The significant robustness having been added to the biocatalytic step by the presence of TPGS-750-M in the medium opens the door to additional, potentially even longer sequences ${ }^{48}$, all in water under very mild conditions, as these enzymes appear to tolerate a mixture of residual catalysts in the pot from previous steps.

Industrial application. The beneficial impact of TPGS-750-M on enzymatic activity was applied to an industrial scale process with the multi-kilogram synthesis of the functionalized chiral 4-piperidinol 6 (Fig. 9). The reaction, performed in TPGS-750-M/ $\mathrm{H}_{2} \mathrm{O}$, was compared to that run using $15 \%$ $\mathrm{DMSO} / \mathrm{H}_{2} \mathrm{O}$, both in a phosphate buffer at $40{ }^{\circ} \mathrm{C}$ using $5 \%$ KRED-EW-124. In aqueous TPGS-750-M the reaction reached $98 \%$ conversion after $25 \mathrm{~h}$, while in $\mathrm{DMSO} / \mathrm{H}_{2} \mathrm{O}$ it stopped at $80 \%$; an additional 2 wt \% of enzyme was necessary to access the same $98 \%$ level of conversion. Extensive optimization also led to an increase of more than $50 \%$ in the 


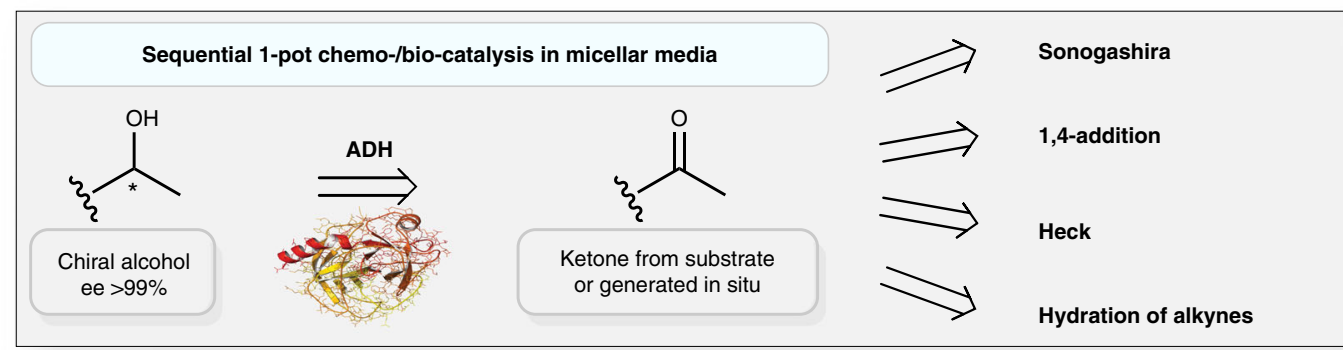

Sonogashira couplings, then ADH
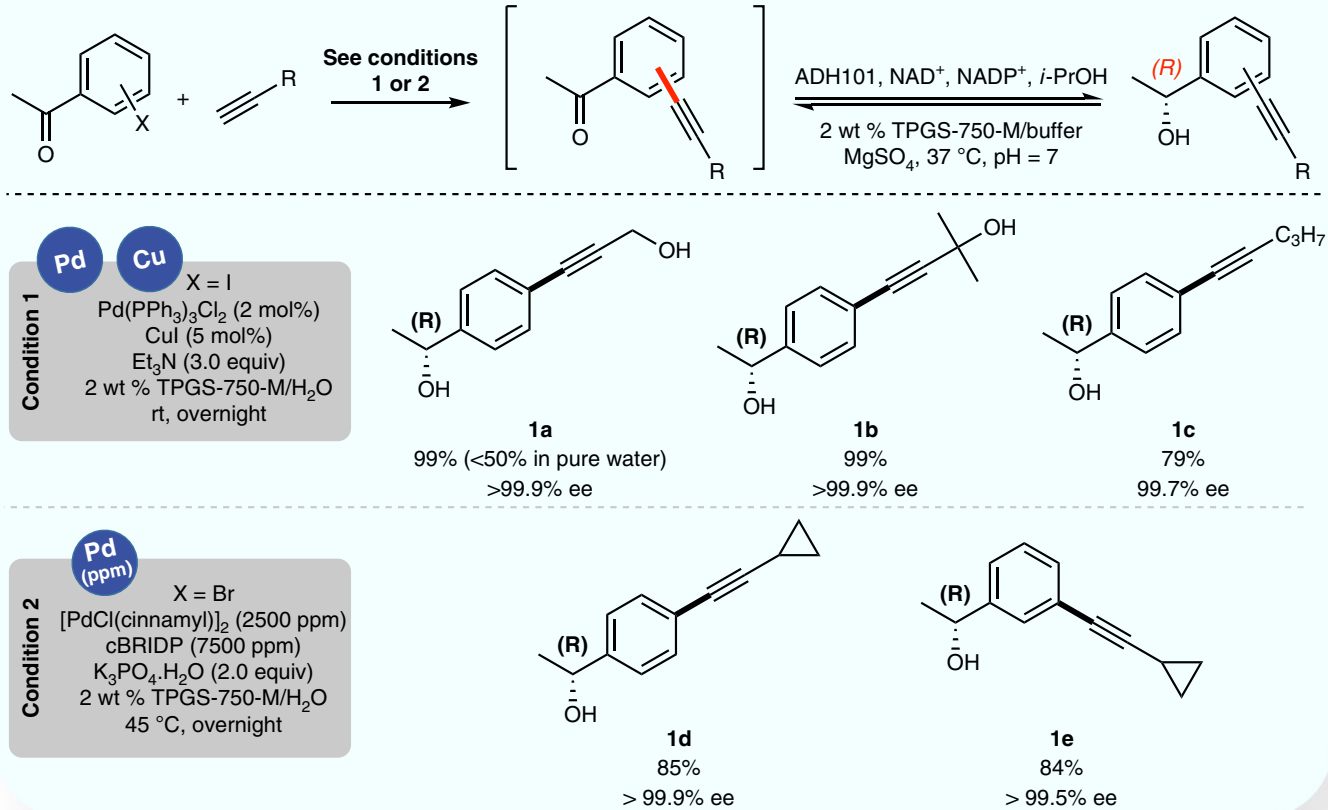

Fig. 5 Sequential Sonogashira coupling/ADH ketone reduction. Sonogashira cross-coupling reactions were followed by asymmetric reduction of the ketone present in each product, mediated by ADH, all in a single pot, enabled by TPGS-750-M

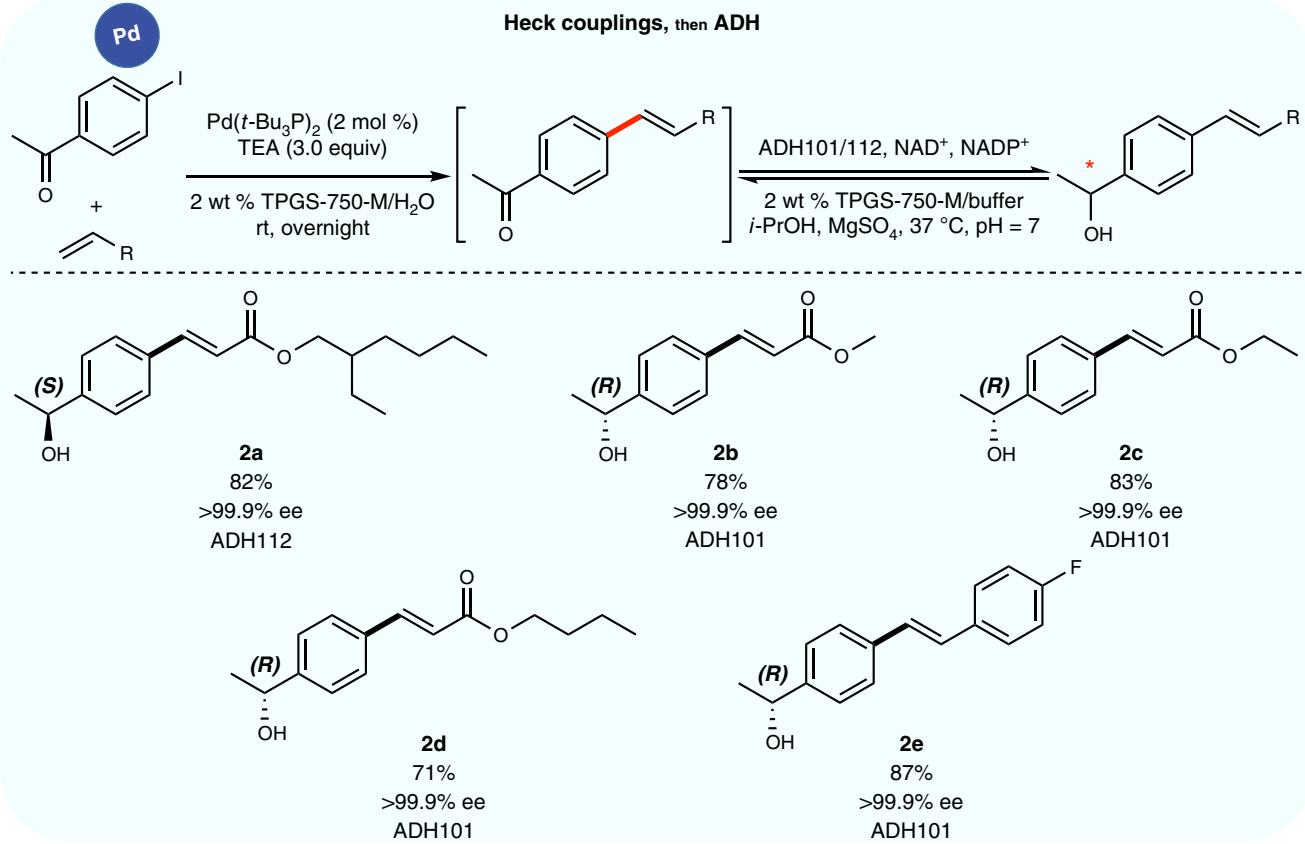

Fig. 6 Sequential Heck cross-coupling/ADH ketone reduction. Heck cross-coupling reactions were followed by asymmetric reduction of the ketone present in each product, mediated by $\mathrm{ADH}$, in aqueous TPGS-750-M 


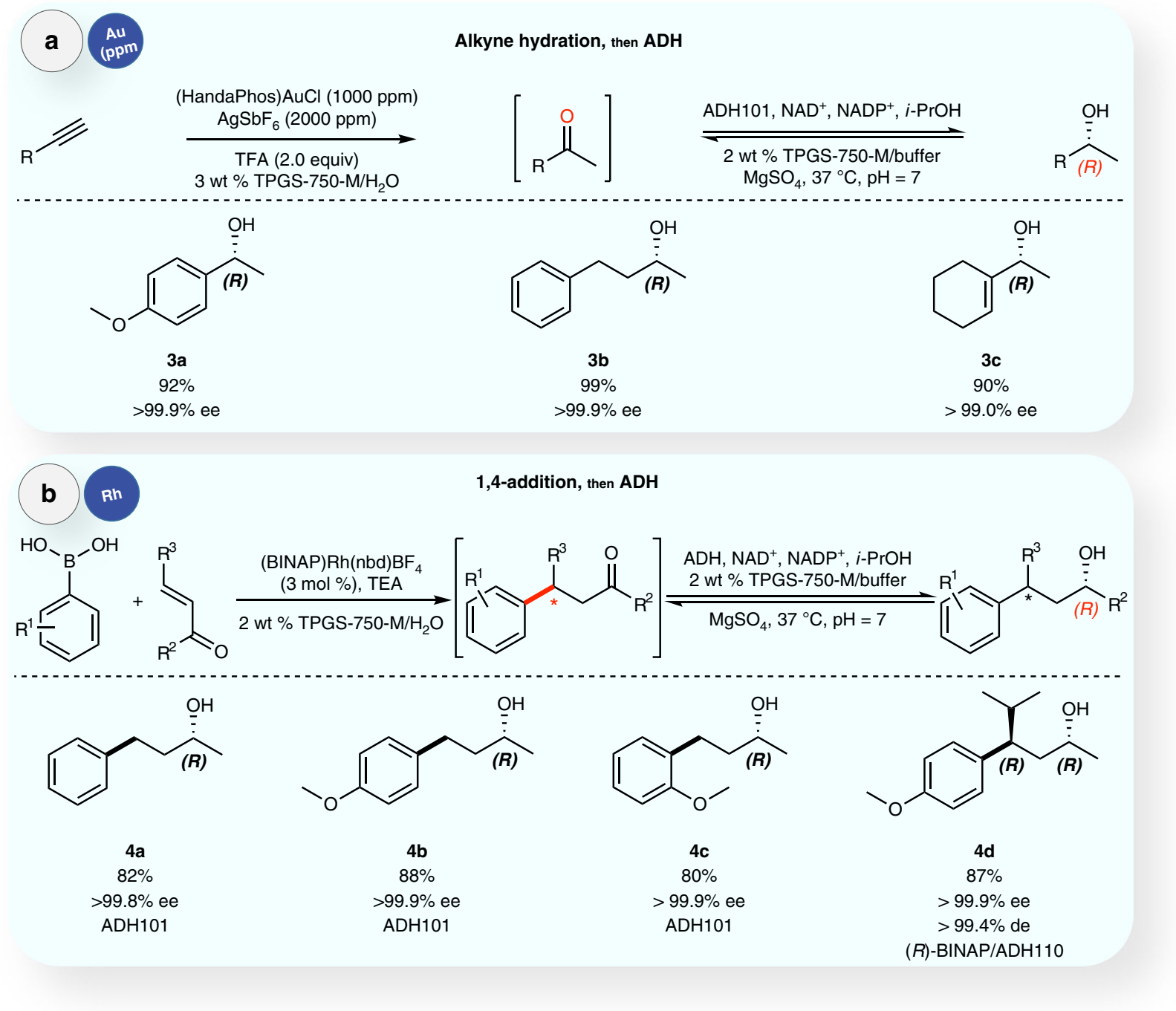

Fig. 7 Transition metal-catalyzed reactions followed by ADH ketone reductions. Plot a describes alkyne hydration reactions followed by the asymmetric reductions of the ketones generated by $\mathrm{ADH101}$; plot $\mathbf{b}$ describes 1,4-addition reactions, followed by $\mathrm{ADH}$-mediated asymmetric reductions of the ketone present in each product, enabled by aqueous TPGS-750-M

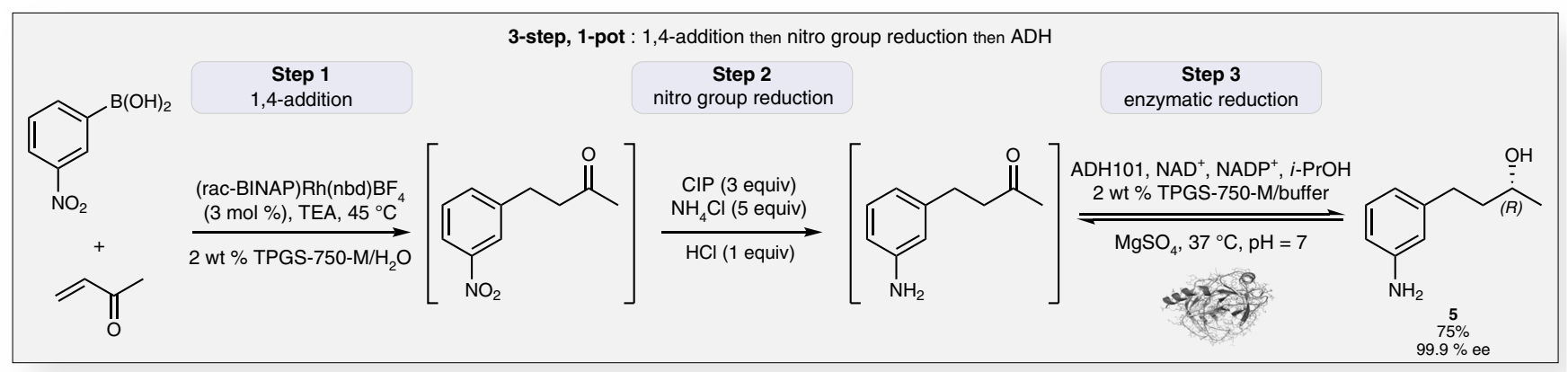

Fig. 8 Sequential reactions combining chemo-catalysis and bio-catalysis. A 1,4-addition reaction was followed by a nitro group reduction, and then an asymmetric reduction of the keto-product mediated by ADH101, all in one-pot and enabled by aqueous TPGS-750-M. The enantiomeric excess (ee) was determined by chiral HPLC after N-acetylation of $\mathbf{5}$ 


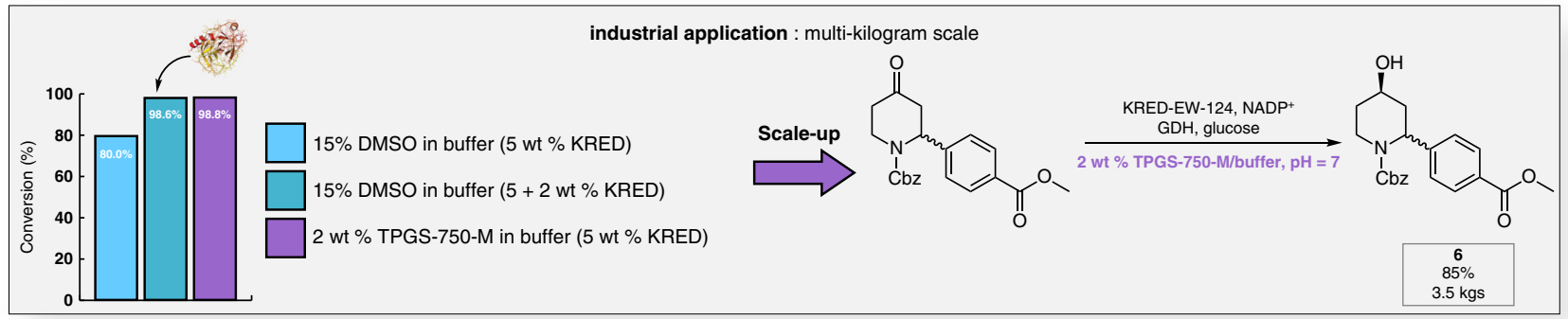

Fig. 9 Industrial application on a $8.2 \mathrm{~mol}$ scale. Comparison on gram scale of the KRED-EW-124 activity in 15\% DMSO vs. TPGS-750-M in buffer, along with scale-up of the synthesis of $\mathbf{6}$ on a multi-kilogram scale. Source data are provided within the Source Data File

concentration in compound $\mathbf{6}$ in the reaction mixture, thus resulting in a substantial increase in productivity. Indeed, compared to an optimized process in DMSO, the approach using TPGS-750-M/ $\mathrm{H}_{2} \mathrm{O}$ leads to a reduction of the Process Mass Intensity (PMI) of more than $32 \%$, and a productivity increase of greater than $40 \%$.

Importantly, evaluation of ADH101 on 4-phenylbut-3-en-2one (Fig. 2d), with $10 \mathrm{v} / \mathrm{v} \%$ of THF in the reaction mixture, commonly used as cosolvent in industrial applications ${ }^{49,50}$, showed no decrease in activity. Likewise, the presence of high concentrations of salts (e.g., $2 \mathrm{M} \mathrm{NaCl})^{51}$ did not alter the outcome. Additionally, the water-soluble surfactant is not extracted with the product and any residual traces can be easily separated by a filtration through a small pad of silica.

Conclusions. Aqueous solutions containing micelles derived from the tailor-made surfactant TPGS-750-M are shown to be not only fully compatible with alcohol dehydrogenase, but also responsible for enhancing enzymatic activity, especially towards highly lipophilic substrates. While no direct interactions are detected between both nanoreactors in the aqueous medium (i.e., micelles and enzymes), the former appear to serve as reservoirs for substrates (and presumably catalysts), thereby moderating the degree of enzyme saturation. Chemo- and bio-catalysis can now be combined in a one-pot sequential fashion, both run under mild conditions, leading to virtually stereopure products of greater complexities. Use of the surfactant also clearly increases the productivity associated with large-scale applications. These results suggest that similar outcomes might be anticipated using other types of enzymatic processes based on readily available kits, in addition to sequences that take advantage of both types of reaction media that exist, by definition, under micellar catalysis conditions (e.g., a coupling reaction followed by two successive enzymatic reactions). These approaches are under active investigation in our laboratories and will be reported in due course.

\section{Methods}

Sonogashira-Condition 1. To a dried $1 \mathrm{dr}$ vial were added, under an argon atmosphere, $\mathrm{Pd}\left(\mathrm{PPh}_{3}\right)_{3} \mathrm{Cl}_{2}(2.8 \mathrm{mg}, 2 \mathrm{~mol} \%)$, $\mathrm{CuI}(1.9 \mathrm{mg}, 5 \mathrm{~mol} \%)$, aryl iodide (1 equiv, $0.2 \mathrm{mmol}$ ), alkyne ( 1.5 equiv, $0.3 \mathrm{mmol})$ and $\mathrm{Et}_{3} \mathrm{~N}(84 \mu \mathrm{L}, 3$ equiv). The vial was capped with a rubber septum. A $2 \mathrm{wt} \%$ TPGS-750-M/ $\mathrm{H}_{2} \mathrm{O}(0.4 \mathrm{~mL})$ was added. The reaction was stirred at room temperature (rt) under argon until completion. The $\mathrm{pH}$ was adjusted to 7 with a solution of $\mathrm{HCl}(1 \mathrm{M})$.

Sonogashira-Condition 2. To a dried $1 \mathrm{dr}$ vial was added, under an argon atmosphere, $100 \mu \mathrm{L}$ of the stock solution containing $[\mathrm{PdCl}(\text { cinnamyl })]_{2}(2.6 \mathrm{mg}$, $2500 \mathrm{ppm})$ and cBRIDP $(10.6 \mathrm{mg}, 7500 \mathrm{ppm})$ in dry THF $(2 \mathrm{~mL})$. The vial was capped with a rubber septum. THF was evaporated with a stream of argon. $\mathrm{K}_{3} \mathrm{PO}_{4} \cdot \mathrm{H}_{2} \mathrm{O}$ (92.1 mg, 2 equiv, $0.4 \mathrm{mmol}$ ), ketone (1 equiv, $0.2 \mathrm{mmol}$ ) and alkyne (1.2 equiv, $0.24 \mathrm{mmol}$ ) were added to the vial. The vial was capped again. $2 \mathrm{wt} \%$ TPGS-750-M/ $\mathrm{H}_{2} \mathrm{O}(0.4 \mathrm{~mL})$ was added and the reaction was stirred at $45^{\circ} \mathrm{C}$ under argon atmosphere for $24 \mathrm{~h}$. The $\mathrm{pH}$ was adjusted to 7 with a solution of $\mathrm{HCl}(1 \mathrm{M})$.
Heck. To a dried $1 \mathrm{dr}$ vial were added, under an argon atmosphere, $\mathrm{Pd}\left(\mathrm{P}\left(t-\mathrm{Bu}_{3}\right)\right)_{2}$ $(2.0 \mathrm{mg}, 2 \mathrm{~mol} \%$ ), aryl iodide ( 1 equiv, $0.2 \mathrm{mmol}$ ), alkene ( 2 equiv, $0.4 \mathrm{mmol}$ ) and $\mathrm{Et}_{3} \mathrm{~N}$ ( 3 equiv, $84 \mu \mathrm{L}$ ). The vial was capped with a rubber septum. A $2 \mathrm{wt} \% \mathrm{TPGS}-$ $750-\mathrm{M} / \mathrm{H}_{2} \mathrm{O}(0.4 \mathrm{~mL})$ was added. The reaction was stirred at $\mathrm{rt}$ under argon for 24 h. The $\mathrm{pH}$ was adjusted to 7 with a solution of $\mathrm{HCl}(1 \mathrm{M})$.

Hydration. To a dried $1 \mathrm{dr}$ vial was added, under an argon atmosphere, $0.2 \mathrm{~mL}$ $(1000 \mathrm{ppm})$ of a gold pre-catalyst solution containing HandaPhos-gold(I) chloride $(0.8 \mathrm{mg}, 0.001 \mathrm{mmol})$ and silver(I)hexafluoroantimonate $(0.7 \mathrm{mg}, 0.002 \mathrm{mmol})$ in dichloromethane $(1 \mathrm{~mL})$. The vial was capped with a rubber septum. Dichloromethane was evaporated under argon. Alkyne $(0.2 \mathrm{mmol}, 1.0$ equiv) was added to the vial, followed by toluene $(20 \mu \mathrm{L})$, a $3 \mathrm{wt} \%$ TPGS-750-M/ $\mathrm{H}_{2} \mathrm{O}$ solution $(0.2$ $\mathrm{mL}, 1.0 \mathrm{M}$ ), and trifluoroacetic acid ( $46 \mathrm{mg}, 0.4 \mathrm{mmol}, 2.0$ equiv). The resulting mixture was stirred at $\mathrm{rt}$ for $24 \mathrm{~h}$. The $\mathrm{pH}$ was adjusted to 7 with a solution of $\mathrm{NaOH}(1 \mathrm{M})$

1-4 addition. To a capped dried $1 \mathrm{dr}$ vial was added, under an argon atmosphere, $0.2 \mathrm{~mL}(3 \mathrm{~mol} \%)$ of the stock solution containing $\mathrm{Rh}(\mathrm{nbd})_{2} \mathrm{BF}_{4}(11.2 \mathrm{mg})$ and BINAP $(18.7 \mathrm{mg})$ in dichloromethane $(1 \mathrm{~mL})$. Dichloromethane was evaporated under argon. Boronic acid $(0.2 \mathrm{mmol}, 1.0$ equiv), followed by a $2 \mathrm{wt} \%$ TPGS$750-\mathrm{M} / \mathrm{H}_{2} \mathrm{O}$ solution $(0.4 \mathrm{~mL}, 0.5 \mathrm{M})$ and TEA $(84 \mu \mathrm{L}, 0.6 \mathrm{mmol}, 3.0$ equiv) were added in succession. The reaction was stirred for $15 \mathrm{~min}$ until homogeneous. Vinyl ketone was then added $(0.2 \mathrm{mmol}, 1.0$ equiv). The reaction was stirred $12 \mathrm{~h}$ at rt. No $\mathrm{pH}$ adjustment was required.

ADH. The concentration was adjusted to $[0.056 \mathrm{M}]$ by adding $2.6 \mathrm{~mL}$ of a $2 \mathrm{wt} \%$ TPGS-750-M/buffer solution (phosphate, $[0.23 \mathrm{M}], \mathrm{pH}=7$ ). $\mathrm{MgSO}_{4}(0.8 \mathrm{mg}$ ), $\mathrm{NAD}^{+}(2.6 \mathrm{mg}), \mathrm{NADP}^{+}(2.4 \mathrm{mg}), i-\mathrm{PrOH}(0.6 \mathrm{~mL})$ and $\mathrm{ADH} 101$ or ADH112 $(20.0 \mathrm{mg})$ were added in succession. The reaction was stirred at $37^{\circ} \mathrm{C}$ until completion. The reaction was extracted in EtOAc. The organic layer was washed with $\mathrm{H}_{2} \mathrm{O}$, dried over anhydrous $\mathrm{MgSO}_{4}$, filtered and concentrated under vacuum. The product was purified by flash chromatography.

\section{Data availability}

All data relevant to this study are available from the corresponding author upon reasonable request. The source data underlying Figs. $2 \mathrm{a}-\mathrm{d}, 3,4 \mathrm{a}-\mathrm{c}, 9$ and Supplementary Figs. 1, 2, 3, 7, 9, 10, 11 and 12 are provided as a Source Data file.

Received: 22 November 2018 Accepted: 22 March 2019

Published online: 15 May 2019

\section{References}

1. Reetz, M. T. Biocatalysis in organic chemistry and biotechnology: past, present, and future. J. Am. Chem. Soc. 135, 12480-12496 (2013).

2. Wohlgemuth, R. Biocatalysis-key to sustainable industrial chemistry. Curr. Opin. Biotechnol. 21, 713-724 (2010).

3. de Souza, R. O. M. A., Miranda, L. S. M. \& Bornscheuer, U. T. A Retrosynthesis approach for biocatalysis in organic synthesis. Chem. Eur. J. 23 12040-12063 (2017).

4. Sheldon, R. A. \& Brady, D. Broadening the Scope of Biocatalysis in Sustainable Organic Synthesis. ChemSusChem 12, 1-24 (2019).

5. Arnold, F. H. Directed evolution: bringing new chemistry to life. Angew. Chem. Int. Ed. 57, 4143-4148 (2018).

6. Hammer, S. C., Knight, A. M. \& Arnold, F. H. Design and evolution of enzymes for non-natural chemistry. Curr. Opin. Green Sustain. Chem. 7, 23-30 (2017). 
7. Engström, K. et al. Co-immobilization of an enzyme and a metal into the compartments of mesoporous silica for cooperative tandem catalysis: an artificial metalloenzyme. Angew. Chem. Int. Ed. 52, 14006-14010 (2013).

8. Rudroff, F. et al. Opportunities and challenges for combining chemo- and biocatalysis. Nat. Catal. 1, 12-22 (2018).

9. Castro, G. R. \& Knubovets, T. Homogeneous biocatalysis in organic solvents and water-organic mixtures. Crit. Rev. Biotechnol. 23, 195-231 (2003).

10. Sheldon, R. A. \& Woodley, J. M. Role of biocatalysis in sustainable chemistry. Chem. Rev. 118, 801-838 (2018).

11. Hoang, H. N. \& Matsuda, T. Chapter 1 - Biotransformation Using Liquid and Supercritical CO2. In Future Directions in Biocatalysis (Second Edition) (ed. Matsuda, T., Japan) pp. 3-25 (Elsevier, 2017). https://doi.org/10.1016/ B978-0-444-63743-7.00001-9.

12. Rantwijk, Fvan \& Sheldon, R. A. Biocatalysis in ionic liquids. Chem. Rev. 107, 2757-2785 (2007).

13. Itoh, T. Ionic liquids as tool to improve enzymatic organic synthesis. Chem. Rev. 117, 10567-10607 (2017).

14. Paul, C. E. \& Fernández, V. G. Chapter 2 - Biocatalysis and Biotransformation in Ionic Liquids. In Ionic Liquids in Lipid Processing and Analysis (eds. Xu, X., Guo, Z. \& Cheong, L.-Z., China) pp. 11-58 (AOCS Press, 2016). https://doi. org/10.1016/B978-1-63067-047-4.00002-7.

15. Xu, P., Zheng, G.-W., Zong, M.-H., Li, N. \& Lou, W.-Y. Recent progress on deep eutectic solvents in biocatalysis. Bioresour. Bioprecessing 4, 34 (2017).

16. Cicco, L. et al. Programming cascade reactions interfacing biocatalysis with transition-metal catalysis in Deep Eutectic Solvents as biorenewable reaction media. Green Chem. 20, 3468-3475 (2018).

17. Hammerer, F. et al. Solvent-free enzyme activity: quick, high-yielding mechanoenzymatic hydrolysis of cellulose into glucose. Angew. Chem. Int. Ed. 57, 2621-2624 (2018).

18. Ryan, J. D. \& Clark, D. S. P450cam biocatalysis in surfactant-stabilized twophase emulsions. Biotechnol. Bioeng. 99, 1311-1319 (2008).

19. Abe, K., Goto, M. \& Nakashio, F. Surfactant-chymotrypsin complex as a novel biocatalyst in organic media. J. Ferment. Bioeng. 83, 550-560 (1997).

20. Andersson, M. P., Gallou, F., Klumphu, P., Takale, B. S. \& Lipshutz, B. H. Structure of nanoparticles erived from designer surfactant TPGS-750-M in water at room temperature. Chem. Eur. J. 24, 6778-6786 (2018).

21. Lipshutz, B. H. et al. TPGS-750-M: a second-generation amphiphile for metalcatalyzed cross-couplings in water at room temperature. J. Org. Chem. 76, 4379-4391 (2011).

22. Lipshutz, B. H. When does organic chemistry follow nature's lead and "make the switch"?. J. Org. Chem. 82, 2806-2816 (2017).

23. Lipshutz, B. Synthetic chemistry in a water world. New rules ripe for discovery. Curr. Opin. Green Sustain. Chem. 11, 1-8 (2018).

24. Wallace, S. \& Balskus, E. Designer Micelles accelerate flux through engineered metabolism in E. coli and support biocompatible chemistry. Angew. Chem. Int. Ed. 50, 6023-6027 (2016).

25. Niefind, K., Müller, J., Riebel, B., Hummel, W. \& Schomburg, D. The crystal structure of R-specific alcohol dehydrogenase from Lactobacillus brevis suggests the structural basis of its metal dependency. J. Mol. Biol. 327, 317-328 (2003).

26. Rodriguez, C. et al. Steric vs. electronic effects in the Lactobacillus brevis ADH-catalyzed bioreduction of ketones. Org. Biomol. Chem. 12, 673-681 (2014).

27. Schlieben, N. H. et al. Atomic resolution structures of R-specific alcohol dehydrogenase from Lactobacillus brevis provide the structural bases of its substrate and cosubstrate specificity. J. Mol. Biol. 349, 801-813 (2005).

28. Leuchs, S. \& Greiner, L. Alcohol dehydrogenase from Lactobacillus brevis: a versatile robust catalyst for enantioselective. Transformation Chem. Biochem. Eng. Q. 25, 267-281 (2011).

29. Abokitse, K. \& Hummel, W. Cloning, sequence analysis, and heterologous expression of the gene encoding a (S)-specific alcohol dehydrogenase from Rhodococcus erythropolis DSM 43297. Appl. Microbiol. Biotechnol. 62 , 380-386 (2003).

30. Weckbecker, A. \& Hummel, W. Cloning, expression, and characterization of an (R)-specific alcohol dehydrogenase from Lactobacillus kefir. Biocatal. Transform. 24, 380-389 (2006).

31. Karabec, M. et al. Structural insights into substrate specificity and solvent tolerance in alcohol dehydrogenase ADH-'A' from Rhodococcus ruber DSM 44541. Chem. Commun. 46, 6312-6316 (2010).

32. Kosjek, B. et al. Purification and characterization of a chemotolerant alcohol dehydrogenase applicable to coupled redox reactions. Biotechnol. Bioeng. 86, 55-62 (2004)
33. Zhou, J. et al. Enzymatic reaction medium containing surfactant. WO2018134710 (2018)

34. Lipshutz, B. H., Ghorai, S. \& Cortes-Clerget, M. The hydrophobic effect applied to organic synthesis: recent synthetic chemistry "in water". Chem. Eur. J. 24, 6672-6695 (2018).

35. Gröger, H. Metals and Metal Complexes in Cooperative Catalysis with Enzymes within Organic-Synthetic One-Pot Processes. In Cooperative Catalysis: Designing Efficient Catalysts for Synthesis (ed. Peters, R., Germany) 325-350 (John Wiley \& Sons, Ltd, 2015). https://doi.org/10.1002/ 9783527681020.ch11.

36. Burda, E., Hummel, W. \& Gröger, H. Modular chemoenzymatic one-pot syntheses in aqueous media: combination of a palladium-catalyzed crosscoupling with an asymmetric biotransformation. Angew. Chem. Int. Ed. 47, 9551-9554 (2008).

37. Prastaro, A. et al. Suzuki-Miyaura cross-coupling catalyzed by proteinstabilized palladium nanoparticles under aerobic conditions in water: application to a one-pot chemoenzymatic enantioselective synthesis of chiral biaryl alcohols. Green Chem. 11, 1929-1932 (2009).

38. Gauchot, V., Kroutil, W. \& Schmitzer, A. R. Highly recyclable chemo-/ biocatalyzed cascade reactions with ionic liquids: one-pot synthesis of chiral biaryl alcohols. Chem. Eur. J. 16, 6748-6751 (2010).

39. Borchert, S., Burda, E., Schatz, J., Hummel, W. \& Gröger, H. Combination of a Suzuki cross-coupling reaction using a water-soluble palladium catalyst with an asymmetric enzymatic reduction towards a one-pot process in aqueous medium at room temperature. J. Mol. Catal. B Enzym. 84, 89-93 (2012).

40. Burda, E., Bauer, W., Hummel, W. \& Gröger, H. Enantio- and diastereoselective chemoenzymatic synthesis of C2-symmetric biarylcontaining diols. ChemCatChem 2, 67-72 (2010).

41. Sgalla, S. et al. Chiral (R)- and (S)-allylic alcohols via a one-pot chemoenzymatic synthesis. Tetrahedron Asymmetry 18, 2791-2796 (2007).

42. Boffi, A. et al. The Heck reaction of allylic alcohols catalyzed by palladium nanoparticles in water: chemoenzymatic synthesis of (R)-()-rhododendrol. ChemCatChem 3, 347-353 (2011).

43. Viparelli, P., Alfani, F. \& Cantarella, M. Models for enzyme superactivity in aqueous solutions of surfactants. Biochem. J. 344, 765-773 (1999).

44. Myers, D. Surfactant Science and Technology, 3rd edn (John Wiley \& Sons Inc, New Jersey, New York, 2006).

45. Lipshutz, B. H. \& Taft, B. R. Heck couplings at room temperature in nanometer aqueous Micelles. Org. Lett. 10, 1329-1332 (2008)

46. Klumphu, P. et al. Micellar catalysis-enabled sustainable ppm Aucatalyzed reactions in water at room temperature. Chem. Sci. 8, 6354-6358 (2017).

47. Lipshutz, B. H., Isley, N. A., Moser, R., Leuser, H. \& Taft, B. R. $\mathrm{Rh}$-catalyzed asymmetric 1,4 -addition reactions in water at room temperature with in-flask catalyst recycling. Adv. Synth. Catal. 354 , 3175-3179 (2012)

48. Gallou, F., Isley, N. A., Ganic, A., Onken, U. \& Parmentier, M. Surfactant technology applied toward an active pharmaceutical ingredient: more than a simple green chemistry advance. Green Chem. 18, 14-19 (2016).

49. Gabriel, C. M. et al. Effects of co-solvents on reactions run under Micellar catalysis conditions. Org. Lett. 19, 194-197 (2017).

50. Gallou, F., Guo, P., Parmentier, M. \& Zhou, J. A general and practical alternative to polar aprotic solvents exemplified on an amide bond formation. Org. Process Res. Dev. 20, 1388-1391 (2016).

51. Lipshutz, B. H., Ghorai, S., Leong, W. W. Y. \& Taft, B. R. Manipulating Micellar environments for enhancing transition metal-catalyzed crosscouplings in water at room temperature. J. Org. Chem. 76, 5061-5073 (2011).

\section{Acknowledgements}

We gratefully acknowledge support for this work from the NSF (GOALI SusChEM 1566212) and Novartis, especially Gai, Yu, Wang, Ruidong, Kong, Weiyong, Lu, Yadong, Min Shi, Weiyong Kong for their experimental contributions. This research also made use of the NMR facility (NIH Shared Instrumentation Grant SIG 1S10OD012077). The authors acknowledge with thanks Prof. Norbert O. Reich (UCSB) for many insightful comments and fruitful discussions, Dr. Martin Kurnik for his help on CD acquisition, Dr. Hongjun Zhou for NMR analysis and Dr. Aidan Taylor for his assistance in acquiring cryo-TEM images.

\section{Author contributions}

All authors contributed equally to the conception and the design of this work. M.C.-C and N.A. designed the experiments and analyzed the data. J.Z., F.G., M.P. and F.G. contributed to the industrial study. J.-Y.B. reviewed the MS. M.C.-C. wrote the manuscript. B.H.L. directed the work. 


\section{Additional information}

Supplementary Information accompanies this paper at https://doi.org/10.1038/s41467019-09751-4.

Competing interests: The authors declare no competing interests.

Reprints and permission information is available online at http://npg.nature.com/ reprintsandpermissions/

Journal peer review information: Nature Communications thanks Rafael Luque, Reinhard Schomäcker and the other anonymous reviewer(s) for their contribution to the peer review of this work.

Publisher's note: Springer Nature remains neutral with regard to jurisdictional claims in published maps and institutional affiliations. (c) Open Access This article is licensed under a Creative Commons Attribution 4.0 International License, which permits use, sharing, adaptation, distribution and reproduction in any medium or format, as long as you give appropriate credit to the original author(s) and the source, provide a link to the Creative Commons license, and indicate if changes were made. The images or other third party material in this article are included in the article's Creative Commons license, unless indicated otherwise in a credit line to the material. If material is not included in the article's Creative Commons license and your intended use is not permitted by statutory regulation or exceeds the permitted use, you will need to obtain permission directly from the copyright holder. To view a copy of this license, visit http://creativecommons.org/licenses/by/4.0/.

(C) The Author(s) 2019 